\title{
Mental health difficulties of adults with COVID-19-like symptoms in Bangladesh: a case control-study
}

\author{
Musammet Rasheda Begum ${ }^{1 \#, ~ M d ~ S h a f i q u l ~ I s l a m ~ K h a n ~}{ }^{2 \#}$, Md. Hasan Al Banna ${ }^{2}$, Satyajit Kundu ${ }^{3}$, Md \\ Munnaf Hossen ${ }^{4}$, Md. Abu Sayeed ${ }^{5 *}$, Enryka Christopher ${ }^{6}$, M. Tasdik Hasan ${ }^{7}$, Sabrina Saba ${ }^{8}$, Tapos \\ Kormoker',_Md. Shamsuzzoha ${ }^{10}$
}

${ }^{1}$ Department of Agricultural Economics and Social Sciences, Chattogram Veterinary and Animal Sciences University, Chattogram-4225, Bangladesh.

${ }^{2}$ Department of Food Microbiology, Patuakhali Science and Technology University, Patuakhali- 8602, Bangladesh.

${ }^{3}$ Department of Biochemistry and Food Analysis, Patuakhali Science and Technology University, Patuakhali - 8602, Bangladesh.

${ }^{4}$ Department of Immunology, Shenzhen University, Shenzhen, Guangdong, 518060, CN.

${ }_{5}^{5}$ Department of Post-Harvest Technology and Marketing, Patuakhali Science and Technology University, Patuakhali- 8602, Bangladesh. Orchid Id: https://orcid.org/0000-0003-0745-1755

${ }^{6}$ Harvard T.H. Chan School of Public Health, Boston, MA, USA.

${ }^{7}$ Department of Primary Care \& Mental Health, University of Liverpool, Liverpool, UK.

${ }^{8}$ School of Public Health, University of Alberta, Canada

${ }^{9}$ Department of Emergency Management, Patuakhali Science and Technology University, Dumki, Patuakhali-8602, Bangladesh

${ }^{10}$ Department of Emergency Management, Patuakhali Science and Technology University, Dumki, Patuakhali-8602, Bangladesh

\#These two authors has similar contribution

*Corresponding author:

Abu Sayeed,

Department of Post-Harvest Technology and Marketing, Patuakhali Science and Technology University, Patuakhali- 8602, Bangladesh.

Mail address: shuvo.nfs.pstu@gmail.com 


\begin{abstract}
Introduction

The rapid spread of SARS-CoV-2 coupled with inefficient testing capacities in Bangladesh has resulted in a number of deaths from COVID-19-like symptoms that have no official test results. Insufficient test sites and healthcare facilities catered to COVID-19 has led to feelings of fear and frustration in those who are sick. This study was the first study which explored the mental health of adults with the most common COVID-19-like symptoms in Bangladesh.
\end{abstract}

\title{
Methods
}

This retrospective case control study gathered data via an online survey to explore the mental health of Bangladeshi adults with symptoms akin to COVID-19. Level of stress, anxiety symptoms, and depressive symptoms were measured with the DASS-21. Chi-square tests and multivariate logistic regression was performed to examine the association of variables.

\section{Results}

The prevalence rates of anxiety symptoms, and depressive symptoms of overall population were $26.9 \%$ and $52.0 \%$ respectively and $55.6 \%$ reported mild to extremely severe levels of stress. Multivariate logistic regression determined that respondents with COVID-19-like symptoms (case) reported higher odds for stress level (AOR: 2.043; CI: 1.51-2.76), anxiety symptoms (AOR: 2.770; CI: 2.04-3.77) and depressive symptoms (AOR: 1.482; CI: 1.12-1.96) than asymptomatic respondents (control).

\section{Conclusion}

Patients with symptoms like those of COVID-19 should be prioritized in the healthcare setting in order to reduce mental health difficulties throughout the pandemic.

Key Words: Mental Health, COVID-19 like symptoms, Bangladesh, Case-control 


\section{Introduction}

The emergence and progression of the COVID-19 pandemic has received global attention since February of 2020, when the WHO declared the virus a public health emergency. As of July $21^{\text {st }}$ 2020, there are over 14 million cases and over 600 thousand deaths due to COVID-19 (WHO, 2020b). Similar to many countries, Bangladesh instituted precautionary measures, such as lockdowns and quarantines. Unfortunately, however, numbers of infected cases have been increasing within the country. As of July $21^{\text {st }} 2020$, over 200 thousand cases and over 2 thousand COVID-19 deaths have been confirmed in Bangladesh (IEDCR, 2020). Escalating the situation is the fragile health care sector of Bangladesh, which is poorly equipped to deal with an influx of pandemic patients due in part to a lack of testing facilities, RT-PCR equipment, and skilled healthcare workers (Dhakatribune, 2020; Molla, 2020; Sujan \& Hasan, 2020).

Reports are surfacing in Bangladeshi news outlets that, despite the lack of access to COVID-19 tests, general hospitals are refusing to admit patients who cannot prove they have tested negative while hospitals designated specifically for COVID-19 treatment are refusing to admit patients who cannot prove they have tested positive, creating a difficult dilemma for a public with limited access to testing (NEW AGE, 2020b). Thus, Bangladeshi residents with COVID-19-like symptoms are struggling to access adequate healthcare in a hospital setting. A national daily newspaper has reported an increase in deaths from symptoms similar to COVID-19, likely due to too few testing facilities and the resulting hospital refusals (NEW AGE, 2020a). These healthcare issues directly caused by the pandemic exacerbate common mental health distress, such as stress, anxiety and depression, when compounded with socioeconomic problems indirectly caused by the pandemic, such as unemployment and isolation (Anwar, Nasrullah, \& Hosen, 2020).

Additionally, the lack of medical resources and trained personnel negate prompt diagnosis and treatment. Complicating diagnosis decisions further is that the COVID-19 symptoms the lay public are most familiar with - fever, headache, dry cough, breathing difficulties, sore throat and fatigue (Huang et al., 2020) — are quite similar to a normal flu or cold. These factors are likely to cause psychological distress in individuals suffering from any of these common symptoms. This study explored the mental health of adults with the most common COVID-19-like symptoms. We hypothesized that symptomatic respondents would experience more mental health distress than asymptomatic respondents. The main objective of this study is to investigate whether adults with 
COVID-19-like symptoms (case) during the initial pandemic periodic in Bangladesh experience more level of stress, anxiety symptoms, and depressive symptoms than adults who have not had any COVID-19-like symptoms (control).

\section{Methodology}

\section{Study design and respondents}

A retrospective case-control web-based survey was conducted to assess the association of psychological response with COVID-19 like symptoms among the general population from April $29^{\text {th }}$ to May $14^{\text {th }}, 2020$. Data was collected online using a snowball sampling technique, in which the research team distributed the survey link through social media to all divisions of Bangladesh. Among 1427 respondents, 306 reported having experienced COVID-19-like symptoms within the last two weeks. Psychological outcomes were compared between symptomatic and nonsymptomatic cases. As respondents who reported chronic illnesses were excluded from this analysis, a total of 686 asymptomatic, healthy respondents (without COVID-19-like symptoms) were included in the analysis. A symptom list was conceptualized with guidance from coronavirus guidelines published by the World Health Organization (WHO, 2020a). Individuals aged 18 years and older were eligible for the study.

\section{Procedures}

The Research Ethical Committee of the Department of Food Microbiology, Patuakhali Science and Technology University, Bangladesh, approved and reviewed this research protocol (approval no.:FMB:24/04/2020:05). The survey was originally written in English and then translated into Bangla by an expert interpreter. The questionnaire was piloted in a small group of random online users to confirm understanding of the survey questions and rectify any problematic wording. Clicking on the link originally distributed by the research team automatically led respondents to the study overview page and informed consent. This first page included a short overview of the study background, aims, and procedures, eligibility criteria, confidentiality agreement, consent form, instructions and study members' contact information for respondents who had questions or wished for more information. Completion of demographic information was required in order to move forward to the rest of the survey. The survey collection was conducted following the Helsinki Declaration as revised in 2013 (Williams, 2008) and the Checklist for Reporting Results of Internet ESurveys (CHERRIES) guidelines (Eysenbach, 2004). 


\section{Survey contents}

This survey was split into three sections: sociodemographic information, an assessment of COVID-19-like symptoms and a mental health assessment. Sociodemographic information included age, gender, education, residence, monthly income and smoking behavior. The sociodemographic section consisted of a combination of binary-choice ("yes/no") and multiplechoice questions. WHO guidelines on coronavirus advice to the public (WHO, 2020a) were utilized to create a COVID-19-like symptoms checklist for this study. Respondents who reported having any of the checklist symptoms (fever, headache, dry cough, breathing difficulties, sore throat, and fatigue) within last 14 days were considered "symptomatic." This symptoms checklist included binary-choice questions such as, "In the past 14 days, have you experienced any fever?" with answer choices, "yes/ no."

A validated Bangla version of the Depression, Anxiety, and Stress Scale (DASS-21) was used to assess the mental health of respondents (Le et al., 2019)(Alim, Kibria, Uddin, Nessa, \& Wahab, 2014). The DASS-21 contains three self-report scales with a total of 21 -items designed to assess symptoms of the negative domains of depressive symptoms, anxiety symptoms, and stress level (Lovibond \& Lovibond, 1995). Likert scale scores range from 0 (item does not apply at all) to 3 (item applies strongly) for occurrences over the last week. The DASS-21 has proven to be reliable and relevant for assessing mental health in the Bangladeshi population (Alim et al., 2015; Sadiq et al., 2019). The Cronbach's alpha coefficient of the DASS-21 was 0.92, indicating acceptable internal consistency (Taber, 2018). In this study, The Cronbach's alpha coefficient of the DASS21 was 0.87. Prior to this, the DASS-21 was used in SARS research (McAlonan et al., 2007).

\section{Statistical analyses}

Continuous variables were converted into categorical variables for ease of interpretation. A chisquare test and Fisher exact test were used to check the association between various factors and outcome variables. A multivariate logistic regression was conducted to analyses the relationship between predictors (age, gender, education, residence, monthly income and smoking behavior) and outcome variables (stress level, anxiety symptoms and depressive symptoms) after adjusting confounders. Odds ratios (OR) and their respective 95\% confidence intervals are listed. Data were analyzed with SPSS (Statistical Package for Social Sciences), version 23.0. All p-values of less than 0.05 were considered statistically significant. 


\section{Results}

\section{Descriptive}

The mean age of respondents in the symptomatic group $(n=247)$ was 25.5 years (SD: 6.7), while the mean age of respondents in the asymptomatic group $(n=439)$ was 26.5 years (SD: 6.6). The majority $(70.4 \%)$ of the respondents were male. More than half of the respondents were from rural areas $(57.2 \%)$ and completed an undergraduate education (60.8\%). Almost half (43.5\%) of the respondents' monthly income was above 35000 BDT ( 416 USD). Only about one quarter of the respondents were smokers. The prevalence of anxiety symptoms and depressive symptoms of the overall sample were $26.9 \%$ and $52.0 \%$ respectively and $55.6 \%$ reported mild to extremely severe levels of stress, whereas the prevalence of anxiety symptoms and depression of the symptomatic group were $40.6 \%$ and $60.1 \%$ respectively and $66.2 \%$ reported mild to extremely severe levels of stress. Symptomatic respondents exhibited between 20-30\% higher prevalence estimates of poor mental health than the asymptomatic group. All demographic and mental health variables differed between the symptomatic and asymptomatic groups (Table-1).

\section{Associations between variables}

The stress level experienced by respondents was significantly associated with age $\left(\chi^{2}=23.902\right.$, $p=0.000)$, gender $(13.676,0.000)$, monthly income $(14.594,0.000)$, education $(8.098,0.044)$, and smoking behavior $(9.372,0.002)$. The level of anxiety symptoms experienced by respondents was significantly associated with age $(5.456,0.019)$, gender $(15.655,0.000)$, residence $(18.630,0.000)$, education $(24.857,0.000)$, and smoking behavior $(11.712,0.001)$. The level of depressive symptoms experienced by respondents was significantly associated with age $(47.567,0.00)$, gender (10.321, 0.001), and education (18.632, 0.000) (Table 2).

\section{Odds of poor mental health}

The multivariate logistic regression identified factors associated with poor mental health outcomes after adjusting for confounders (see Table 3). Respondents with the following factors had significantly greater odds of experiencing mild to extreme levels of stress: being 25 years old or younger (OR: 3.242, 95\% CI: 2.26-4.65), having a monthly income above 35000 BDT (1.814, 1.36-2.42), and having experienced COVID-19-like symptoms within the past 14 days (2.043, 
1.51-2.76). Those who completed higher secondary $(0.320,0.19-0.55)$ or undergraduate education $(0.538,0.36-0.80)$ had lower odds of experiencing mild to extreme levels of stress than those who completed a master's degree level or above. Respondents with the following factors had significantly greater odds of experiencing mild to extreme levels of anxiety symptoms: female gender (OR: 1.827, 95\% CI: 1.34-2.49), only having completed secondary education (OR: 12.335, 95\% CI: 3.80-40.01), and having experienced COVID-19-like symptoms within the past 14 days (OR: 2.770, 95\% CI: 2.04-3.77). Respondents with the following factors had significantly greater odds of experiencing mild to extreme levels of depressive symptoms: being 25 years old or younger (OR: 2.44, 95\% CI: 1.86-3.22), female gender (OR: 1.450, 95\% CI: 1.09-1.92), and having experienced COVID-19-like symptoms within the past 14 days (OR: 1.482, 95\% CI: 1.12-

\subsection{6) (Table 3).}

\section{Discussion}

Respondents who experienced COVID-19-like symptoms within the past 14 days roughly had twice the odds of experiencing mild or greater levels of stress symptoms than asymptomatic respondents. Symptomatic respondents had 2.7 times the odds of experiencing mild or greater levels of anxiety symptoms than asymptomatic respondents. Respondents having COVID-19-like symptoms 1.482 times higher odds of depressive symptoms than healthy respondents These findings are similar to another study conducted in China during the COVID-19 pandemic (Wang et al., 2020).

At least 1010 people died in the country with COVID-19 symptoms in 70 days since March 8 and the number of such death is decreasing with the gradual increase in the test for coronavirus, finds a study (NEW AGE, 2020a). The people might not timely tested due to poor health care seeking behavior of people and lack of easy access to test facilities. Still many suspected patients reported a long waiting time to find results after giving sample. Increasing number of testing lab and decentralization of the COVID-19 medical facilities is very important to support the patient. With the Increase of sample collection booth people will be encouraged to give sample earlier and this in turn will reduce the cross contamination in the society.

From the very beginning, there was lack of communication between government and private sector. Unavailability of private doctors and disagreement of private hospitals to take corona 
patients or suspected patients with symptoms making the health care more disrupted. It was stated that 386 people have died with Covid-19 like symptoms in Bangladesh between March 8 and April 30, where 64\% of them died without receiving any treatment (Dhaka Tribune, 2020). The government has issued directives and warnings against treatment refusal, but it has failed to make any noticeable change in the situation. For a long time, there was no specific guideline for hospitals or patients regarding admission and treatment who fail to show 'no COVID19' certification. Even the COVID-19 specialized hospitals refused treatment until patients show 'COVID-19 positive' certification. This situation is still taking a heavy toll in many parts of the country as is evident in the figure of death of patients with COVID-19-like symptoms. The government, therefore, need to take a look into the issue of treatment refusal and testing facilities that are largely viewed responsible for the death of people with COVID-19-like symptoms.

In addition, rumors \& fake news in social media are also responsible for high fear and frustration. Progressive arguments, conversations and alarming developments of fake news and propaganda, leaving people in psychological trauma and anxiety (Ali, 2020). Authentic and transparent print and electronic media may also minimize the fear. E-health or tele- psychiatry services can be potential sources of primary mental health care, which can reduce tension of the scared patients.

There are some limitations; limited research on this emerging topic hindered the robustness of this study's conclusions. Self-reported information is more limited than clinical diagnoses, as they cannot be confirmed. There was a chance of recall bias as it was not possible to validate the information due to the retrospective design of the study. Recruitment methods only captured internet users, which reduces the generalizability of findings. Additionally, other confounding factors, such as domestic violence or exposure stress-inducing media, were not captured in the survey.

\section{Conclusion}

Results suggest a high proportion of respondents with COVID-19-like symptoms showed higher stress level, anxiety symptoms and depressive symptoms. National and international organizations have already called for actions to reduce the mental health burden created by this pandemic. Specific attention should be given for COVID-19 like symptomatic patients to reduce the burden of mental health difficulties amid this crisis period. Compared to its inhabitants and confirmed 
cases, Bangladesh falls behind on the number of tests. Immediate testing and according accessible interventions may reduce the mental illness of the symptomatic but COVID-19 negative patients.

\section{Declaration of Conflicting Interests}

The Author(s) declare(s) that there is no conflict of interest'.

\section{Funding}

None

\section{Acknowledgement}

Authors like to thank the respondents.

\section{References:}

Ali, I. (2020). The COVID-19 Pandemic: Making Sense of Rumor and Fear: Op-Ed. Medical Anthropology, 1-4.

Alim, S. M. A. H. M., Kibria, S. M. E., Uddin, M. Z., Nessa, M., \& Wahab, M. A. (2014). Translation of DASS 21 into Bangla and validation among medical students. Bangladesh Journal of Psychiatry, 28(2), 67-70.

Alim, S. M. A. H. M., Rabbani, M. G., Karim, E., Mullick, M. S. I., Al Mamun, A., \& Khan, M. Z. R. (2015). Assessment of depression, anxiety and stress among first year MBBS students of a public medical college, Bangladesh. Bangladesh Journal of Psychiatry, 29(1), 23-29.

Anwar, S., Nasrullah, M., \& Hosen, M. J. (2020). COVID-19 and Bangladesh: Challenges and how to address them. Frontiers in Public Health, 8.

Dhaka Tribune. (2020). 386 die with coronavirus symptoms in Bangladesh. Published on 3 May, 2020 [online]. Available in https://www.dhakatribune.com/bangladesh/2020/05/03/reportcovid-19-symptoms-killed-386-nationwide-till-april. Accessed on 17 June, 2020.

Dhakatribune. (2020). Covid-19: Immediate Expansion of Testing Labs to Districts Needed. Available online at: https://www.dhakatribune.com/health/coronavirus/2020/04/11/covid- 
19-immediate-expansion-of-testing-labs-to-districts-needed.

Eysenbach, G. (2004). Improving the quality of Web surveys: the Checklist for Reporting Results of Internet E-Surveys (CHERRIES). Journal of Medical Internet Research, 6(3), e34.

Huang, C., Wang, Y., Li, X., Ren, L., Zhao, J., Hu, Y., ... Gu, X. (2020). Clinical features of patients infected with 2019 novel coronavirus in Wuhan, China. The Lancet, 395(10223), 497-506.

IEDCR. (2020). Covid-19 Status Bangladesh. Retrieved from https://www.iedcr.gov.bd/

Le, T. A., Le, M. Q. T., Dang, A. D., Dang, A. K., Nguyen, C. T., Pham, H. Q., ... Vuong, Q.-H. (2019). Multi-level predictors of psychological problems among methadone maintenance treatment patients in difference types of settings in Vietnam. Substance Abuse Treatment, Prevention, and Policy, 14(1), 39.

Lovibond, P. F., \& Lovibond, S. H. (1995). The structure of negative emotional states: Comparison of the Depression Anxiety Stress Scales (DASS) with the Beck Depression and Anxiety Inventories. Behaviour Research and Therapy, 33(3), 335-343.

McAlonan, G. M., Lee, A. M., Cheung, V., Cheung, C., Tsang, K. W. T., Sham, P. C., ... Wong, J. G. W. S. (2007). Immediate and sustained psychological impact of an emerging infectious disease outbreak on health care workers. The Canadian Journal of Psychiatry, 52(4), 241247.

Molla, M.-M. (2020). Govt Now Scrambles for Testing Kits, PPE. Available online at: https://www.thedailystar.net/frontpage/news/govt-now-scramblestesting-kits-ppe-1882633.

NEW AGE. (2020a). 1,010 die with COVID-19 symptoms in 70 days in Bangladesh. [Online]. Available in: https://www.newagebd.net/article/106772/1010-die-with-covid-19-symptomsin-70-days-in-bangladesh. Accessed on 17 June 2020.

NEW AGE. (2020b). Worrying rise of death with COVID-19-like symptoms. Published on 13 June, 2020. [online]. Available in: https://www.newagebd.net/article/108275/worrying-riseof-death-with-covid-19-like-symptoms. Accessed on 17 June, 2020. 
Sadiq, M. S., Morshed, N. M., Rahman, W., Chowdhury, N. F., Arafat, S. M. Y., \& Mullick, M. S. I. (2019). Depression, Anxiety, Stress among Postgraduate Medical Residents: A Cross sectional Observation in Bangladesh. Iranian Journal of Psychiatry, 14(3), 192.

Sujan, M., \& Hasan, R. (2020). Coronavirus Outbreak: Screening Still Lax at Dhaka Airport. Available online at: https://www.thedailystar.net/frontpage/news/coronavirus-outbreak screening-still-lax-dhaka-airport-1878607.

Taber, K. S. (2018). The use of Cronbach's alpha when developing and reporting research instruments in science education. Research in Science Education, 48(6), 1273-1296.

Wang, C., Pan, R., Wan, X., Tan, Y., Xu, L., Ho, C. S., \& Ho, R. C. (2020). Immediate psychological responses and associated factors during the initial stage of the 2019 coronavirus disease (COVID-19) epidemic among the general population in China. International Journal of Environmental Research and Public Health, 17(5), 1729.

WHO. (2020a). Coronavirus disease (COVID-19) advice for the public. Retrieved from https://www.who.int/emergencies/diseases/novel-coronavirus-2019/advice-for-public

WHO. (2020b). Coronavirus disease (COVID-19) pandemic. 2020 Available at: https://www.who.int/emergencies/diseases/novel-coronavirus-2019; [Accessed on 14, June].

Williams, J. R. (2008). The Declaration of Helsinki and public health. Bulletin of the World Health Organization, 86, 650-652. 
Table 1: Demographic characteristics of study participants (n=994)

\begin{tabular}{|c|c|c|c|c|c|}
\hline \multirow[t]{2}{*}{ Variables } & \multirow[t]{2}{*}{ Categories } & \multicolumn{2}{|c|}{ COVID-19 like symptoms } & \multirow{2}{*}{$\begin{array}{c}\text { Total } \\
\mathrm{N}(\%) \\
\end{array}$} & \multirow[t]{2}{*}{ Statistics } \\
\hline & & No, N (\%) & Yes, N (\%) & & \\
\hline \multirow[t]{2}{*}{ Age } & $\leq 25$ years & $439(64.0)$ & $226(73.4)$ & $665(66.9)$ & \multirow{2}{*}{$\chi^{2}=8.450, p=0.004$} \\
\hline & $>25$ years & $247(36.0)$ & $82(26.4)$ & $329(33.1)$ & \\
\hline \multirow[t]{2}{*}{ Gender } & Male & $493(71.9)$ & $207(67.2)$ & $700(70.4)$ & \multirow{2}{*}{$\chi^{2}=2.214, p=0.137$} \\
\hline & Female & $193(28.1)$ & $101(32.8)$ & $294(29.6)$ & \\
\hline \multirow[t]{2}{*}{ Residence } & Rural & $432(63.0)$ & $137(44.5)$ & $569(57.2)$ & \multirow{2}{*}{$\chi^{2}=29.70, p=0.000$} \\
\hline & Urban & $254(37.0)$ & $171(55.5)$ & $425(42.8)$ & \\
\hline \multirow[t]{4}{*}{ Education } & Secondary & $14(2.0)$ & $4(1.3)$ & $18(1.8)$ & \multirow{4}{*}{$\chi^{2}=44.50, p=0.000$} \\
\hline & Higher secondary & $51(7.4)$ & $66(21.4)$ & $117(11.8)$ & \\
\hline & Undergraduate & $424(61.8)$ & $180(58.4)$ & $604(60.8)$ & \\
\hline & Graduate & $197(28.7)$ & $58(18.8)$ & $255(25.7)$ & \\
\hline \multirow[t]{2}{*}{ Monthly income } & $\leq 35,000 \mathrm{BDT}$ & $392(57.1)$ & $170(55.2)$ & $562(56.5)$ & \multirow{2}{*}{$\chi^{2}=0.328, p=0.004$} \\
\hline & $>35,000 \mathrm{BDT}$ & $294(42.9)$ & $138(44.8)$ & $432(43.5)$ & \\
\hline \multirow[t]{2}{*}{ Smoking } & Yes & $169(24.6)$ & $71(23.1)$ & $240(24.1)$ & \multirow{2}{*}{$\chi^{2}=0.291, p=0.590$} \\
\hline & No & $517(75.4)$ & $237(76.9)$ & 754(75.99) & \\
\hline \multirow[t]{5}{*}{ Stress } & Normal & $337(49.1)$ & $104(33.8)$ & $441(44.4)$ & \multirow{5}{*}{$\mathrm{FET}=23.31, \mathrm{p}=0.000$} \\
\hline & Mild & $193(28.1)$ & $114(37.0)$ & $307(30.9)$ & \\
\hline & Moderate & $105(15.3)$ & $58(18.8)$ & $163(16.4)$ & \\
\hline & Severe & $47(6.9)$ & $32(10.4)$ & $79(7.9)$ & \\
\hline & Extremely severe & $4(0.6)$ & $0(0.0)$ & $4(0.4)$ & \\
\hline \multirow[t]{5}{*}{ Anxiety } & Normal & $544(79.3)$ & $183(59.4)$ & $727(73.1)$ & \multirow{5}{*}{$\mathrm{FET}=45.94, \mathrm{p}=0.000$} \\
\hline & Mild & $57(8.3)$ & $36(11.7)$ & $93(9.4)$ & \\
\hline & Moderate & $37(5.4)$ & $35(11.4)$ & $72(7.2)$ & \\
\hline & Severe & $19(2.8)$ & $24(7.8)$ & $43(4.3)$ & \\
\hline & Extremely severe & $29(4.2)$ & $30(9.7)$ & $59(5.9)$ & \\
\hline \multirow[t]{5}{*}{ Depression } & Normal & $354(51.6)$ & 123(39.9) & $477(48.0)$ & \multirow{5}{*}{$\mathrm{FET}=36.48, \mathrm{p}=0.000$} \\
\hline & Mild & $92(13.4)$ & $44(14.3)$ & $136(13.7)$ & \\
\hline & Moderate & $135(19.7)$ & $49(15.9)$ & $184(18.5)$ & \\
\hline & Severe & $54(7.9)$ & $30(9.7)$ & $84(8.5)$ & \\
\hline & Extremely severe & $51(7.4)$ & $62(20.1)$ & $113(11.4)$ & \\
\hline
\end{tabular}


Table 2: Distribution of socio-demographic and health related variables according to psychological characteristics $(n=994)$

\begin{tabular}{|c|c|c|c|c|c|c|c|}
\hline \multirow[t]{2}{*}{ Variables } & \multicolumn{2}{|c|}{ Stress } & \multicolumn{2}{|c|}{ Anxiety } & \multicolumn{2}{|c|}{ Depression } & \multirow[t]{2}{*}{ Statistics } \\
\hline & No & Yes & No & Yes & No & Yes & \\
\hline \multicolumn{8}{|l|}{ Age (years) } \\
\hline$\leq 25$ & $259(58.7)$ & $406(73.4)$ & 471(64.8) & 194(72.7) & $268(56.2)$ & 397(76.8) & \multirow{2}{*}{$\begin{array}{l}\chi^{2}=23.902, \mathrm{P}=0.000^{\mathrm{S}} \\
\chi^{2}=5.456, \mathrm{P}=0.019^{\mathrm{A}} \\
\chi^{2}=47.567, \mathrm{P}=0.00^{\mathrm{D}}\end{array}$} \\
\hline$>25$ & 182(41.3) & 147(26.6) & $256(35.2)$ & $73(27.3)$ & 209(43.8) & $120(23.2)$ & \\
\hline \multicolumn{8}{|l|}{ Gender - n (\%) } \\
\hline Male & $337(76.4)$ & $363(65.6)$ & $538(74.0)$ & $162(60.7)$ & $359(75.3)$ & $341(66.0)$ & \multirow{2}{*}{$\begin{array}{l}\chi^{2}=13.676, \mathrm{P}=0.000^{\mathrm{S}} \\
\chi^{2}=15.655, \mathrm{P}=0.000^{\mathrm{A}} \\
\chi^{2}=10.321, \mathrm{P}=0.001^{\mathrm{s}}\end{array}$} \\
\hline Female & $104(23.6)$ & $190(34.4)$ & $189(26.0)$ & $105(39.3)$ & $118(24.7)$ & $176(34.0)$ & \\
\hline \multicolumn{8}{|l|}{ Residence } \\
\hline Rural & $256(58.0)$ & $313(56.6)$ & $446(61.3)$ & $123(46.1)$ & $265(55.6)$ & $304(58.8)$ & \multirow{2}{*}{$\begin{array}{l}\chi^{2}=0.211, \mathrm{P}=0.646^{\mathrm{S}} \\
\chi^{2}=18.630, \mathrm{P}=0.000^{\mathrm{A}} \\
\chi^{2}=1.068, \mathrm{P}=.302^{\mathrm{D}}\end{array}$} \\
\hline Urban & $185(42.0)$ & $240(43.4)$ & 281(38.7) & $144(53.9)$ & $212(44.4)$ & $213(41.2)$ & \\
\hline \multicolumn{8}{|l|}{ Education } \\
\hline Secondary & $4(0.9)$ & $14(2.5)$ & $4(.6)$ & $14(5.2)$ & $4(.08)$ & $14(2.7)$ & \multirow{4}{*}{$\begin{array}{l}\chi^{2}=8.098, P=0.044^{\mathrm{S}} \\
\chi^{2}=24.857, \mathrm{P}=0.000^{\mathrm{A}} \\
\chi^{2}=18.632, \mathrm{P}=0.000^{\mathrm{D}}\end{array}$} \\
\hline Higher secondary & $63(14.3)$ & $54(9.8)$ & $83(11.4)$ & $34(12.7)$ & $52(10.9)$ & $65(12.6)$ & \\
\hline Undergraduate & $264(59.9)$ & $340(61.5)$ & $450(61.9)$ & $154(57.7)$ & $272(57.0)$ & $332(64.2)$ & \\
\hline Graduate & $110(24.9)$ & $145(26.2)$ & $190(26.1)$ & $65(24.3)$ & $149(31.2)$ & $106(20.5)$ & \\
\hline \multicolumn{8}{|c|}{ Family monthly income } \\
\hline$\leq 35000 \mathrm{BDT}$ & $279(63.3)$ & $283(51.2)$ & $422(58.0)$ & $140(52.4)$ & $266(55.8)$ & $296(57.3)$ & \multirow{2}{*}{$\begin{array}{l}\chi^{2}=14.594, \mathrm{P}=0.000^{\mathrm{S}} \\
\chi^{2}=2.03, \mathrm{P}=0.114^{\mathrm{A}} \\
\chi^{2}=.224, \mathrm{P}=.636^{\mathrm{D}}\end{array}$} \\
\hline$>35000 \mathrm{BDT}$ & $162(36.7)$ & $270(48.8)$ & $305(42.0)$ & $127(47.6)$ & $211(44.2)$ & $221(42.7)$ & \\
\hline \multicolumn{8}{|l|}{ Smoking status } \\
\hline Yes & $127(28.8)$ & $113(20.4)$ & $196(27.0)$ & $44(16.5)$ & $11(23.3)$ & $129((25.0)$ & \multirow{3}{*}{$\begin{array}{l}\chi^{2}=9.372, \mathrm{P}=0.002^{\mathrm{S}} \\
\chi^{2}=11.712, \mathrm{P}=0.001^{\mathrm{A}} \\
\chi^{2}=.383, \mathrm{P}=.536^{\mathrm{D}}\end{array}$} \\
\hline No & $314(71.2)$ & $440(79.6)$ & $531(73.0)$ & $223(83.5)$ & $366(76.7)$ & $388(75.0)$ & \\
\hline Yes & $104(23.6)$ & $204(36.9)$ & $183(25.2)$ & $125(46.8)$ & $123(25.8)$ & $185(35.8)$ & \\
\hline
\end{tabular}


Table 3: Conditional (forward) logistic regression analyses for factors associated with stress, anxiety and depression of participants $(n=994)$

\begin{tabular}{|c|c|c|c|}
\hline \multirow[t]{2}{*}{ Variables } & \multicolumn{3}{|c|}{ Odds Ratio (95\% CI) } \\
\hline & Stress & Anxiety & Depression \\
\hline \multicolumn{4}{|c|}{ Age (ref.: $>25$ years) } \\
\hline$\leq 25$ years & $3.242(2.26-4.65) * * *$ & - & $2.44(1.86-3.22)^{* * * *}$ \\
\hline \multicolumn{4}{|c|}{ Gender (ref.: male) } \\
\hline Female & - & $1.827(1.34-2.49)^{* * * *}$ & $1.45(1.09-1.92)^{*}$ \\
\hline \multicolumn{4}{|c|}{ Education (ref.: masters and above ) } \\
\hline Secondary & $2.448(0.74-8.14)$ & $12.335(3.80-40.01)^{* * *}$ & - \\
\hline Higher secondary & $0.320(0.19-0.55)^{* * *}$ & $0.848(0.50-1.43)$ & - \\
\hline Undergraduate & $0.538(0.36-0.80)^{* *}$ & $0.962(0.68-1.36)$ & - \\
\hline \multicolumn{4}{|c|}{ Family income (ref.: $\leq 35000$ BDT) } \\
\hline$>35000 \mathrm{BDT}$ & $1.814(1.36-2.42) * * *$ & - & - \\
\hline \multicolumn{4}{|c|}{ COVID-19 like symptoms (ref.: no) } \\
\hline Yes & $2.043(1.51-2.76)^{* * * *}$ & $2.770(2.04-3.77)^{* * *}$ & $1.482(1.12-1.96)^{* *}$ \\
\hline
\end{tabular}

